\title{
ANALISIS POLA PENYEBARAN PENYAKIT DIARE DI KABUPATEN BOGOR
}

\author{
Oleh \\ Fitri Mudia Sari \\ Dosen Matematika Fakultas Matematika dan Ilmu Pengetahuan Alam UNP
}

\begin{abstract}
ABSTRACK
Diarrheal disease is an endemic disease in Indonesia, meaning it occurs continuously in all regions both in the city and in the village, especially in poor areas. In poor areas are generally diarrhea diseases are considered not as a dangerous disease, so the way healing is not through medical treatment. In fact, diarrhea can cause system disturbances or complications that are very harmful for the sufferer. Some of them are fluid and electrolyte disturbances, hypovolemia shock, various body disorders, and if not handled properly can cause death. Thus it becomes important for the nurse to know more about diarrhea, the negative impact it has, and the handling and prevention of its complications.

The objective of this study was to determine the pattern of diarrheal disease spread in Bogor Regency. The method according to the purpose of this research is Ordinary Kriging. To know the distribution of diarrhea disease in Bogor Regency by looking at the result of countour plot. Based on the countour plot, the area that has the highest number of diarrhea sufferers around Barekah and Bojonggenteng villages is marked with White contour color with the range of diarrhea sufferer is 40 - 42 people. Areas with the highest number of diarrheal diseases indicate that the area has a relationship with the number of diarrheal diseases in the surrounding area. Therefore, the area needs to be prioritized in improving water sanitation, counseling to the community and improving health services.
\end{abstract}

Keyword: Diarrhea, Ordinary Kriging, Bogor Regency

\section{PENDAHULUAN}

Penyakit diare masih menjadi salah satu masalah kesehatan yang penting di Indonesia. Padahal sudah berbagai upaya penanganan, baik secara medik maupun upaya perubahan tingkah laku dengan memberikan berbagai penyuluhan kesehatan terus dilakukan. Namun upayaupaya tersebut belum memberikan hasil yang memuaskan.

Diare bisa menyerang siapa saja tanpa mengenal usia. Diare seringkali dianggap penyakit yang biasa dan sering dianggap sepele penanganannya. Pada kenyataanya diare dapat menyebabkan gangguan sistem ataupun komplikasi yang sangat membahayakan bagi penderitanya. Beberapa di antaranya adalah gangguan keseimbangan cairan dan elektrolit, shock hipovolemia, gangguan berbagai organ tubuh, dan bila tidak tertangani dengan baik dapat menyebabkan kematian. Dengan demikian menjadi penting bagi perawat untuk mengetahui lebih lanjut tentang diare, dampak negative yang ditibulkan, serta upaya penanganan dan pencegahan komplikasinya. Penyakit diare bisa dikatakan sebagai penyakit endemis di Indonesia, artinya terjadi secara terus menerus di semua daerah baik di kota maupun di desa, khususnya di daerahdaerah miskin. Di kawasan miskin tersebut umumnya penyakit diare dianggap bukan 
sebagai penyakit yang berbahaya, sehingga cara penyembuhannya tidak melalui pengobatan medik (Sunoto, 1987). Kesenjangan pemahaman mengenai kesehatan tubuh ini disebabkan karena masyarakat menyimpulkan sendiri arti sehat dan sakit sesuai dengan pengalaman hidupnya atau nilai-nilai yang diturunkan oleh generasi-generasi sebelumnya (Wolinsky, 1988). Artinya, masyarakat lapisan bawah seringkali mendefinisikan dirinya sakit tergantung pada persepsi dirinya akan penyakit tersebut. Mereka berpendapat bahwa diare merupakan penyakit yang serius ketika penyakit tersebut telah mengganggu mereka dalam melaksanakan aktivitas sehari-hari.

Berdasarkan uraian di atas maka penelitian ini bertujuan untuk mengetahui pola penyebaran penyakit diare di Kabupaten Bogor. Data yang digunakan adalah data jumlah penderita diare di Kabupaten Bogor pada Desember 2009.

\section{TINJAUAN PUSTAKA}

\section{Metode Kriging}

Kriging merupakan metode geostatistika yang dirancang untuk menduga nilai dari sebuah titik sebagai kombinasi linier dari nilai contoh yang terdapat disekitar titik yang akan diduga. Metode ini menghasilkan dugaan yang bersifat tak bias linier terbaik (Best Linier Unbiased Estimator).

Metode interpolasi kriging dikembangkan pertama kali 40 tahun yang lalu oleh Georges Matheron dan diberi nama kriging untuk menghormati insinyur pertambangan Afrika yang bernama D.G Krige. Kriging dikembangkan dalam upaya untuk memprediksi cadangan bijih yang lebih akurat. Metode ini banyak digunakan dalam industri mineral dan menjadi alat yang fundamental dalam bidang geostatistik. Selama dekade terakhir, metode ini telah disebarluaskan memasuki bidang-bidang lain.

Kriging adalah metode interpolasi spasial untuk menduga nilai suatu peubah pada lokasi tertentu, berdasarkan lokasi tertentu, berdasarkan nilai terboboti dari peubah yang sama pada lokasi lainnya. Eestimasi nilai dari sebuah titik atau blok sebagai kombinasi linier dari nilai contoh yang terdapat disekitar titik yang akan diestimasi. Kriging didasarkan pada asumsi bahwa parameter yang diinterpolasi dapat diperlakukan sebagai variabel regionalisasi. Bobot kriging diperoleh dari hasil variansi estimasi minimum dengan memperluas penggunaan semi-variogram. Estimator kriging dapat diartikan sebagai variabel tidak bias dan penjumlahan dari keseluruhan bobot adalah satu. Bobot inilah yang dipakai untuk mengestimasi nilai dari ketebalan, ketinggian, kadar atau variabel lain.

Kriging memberikan lebih banyak bobot pada contoh dengan jarak terdekat dibandingkan dengan contoh jarak lebih jauh, kemenerusan dan anisotropi merupakan pertimbangan yang penting dalam kriging, bentuk geometri dari data dan karakter variabel yang diestimasi serta besar dari blok juga ditaksir.

Dalam melakukan interpolasi, kriging menghasilkan hasil yang lebih baik dari metode interpolasi Invers distance. Meskipun invers distance lebih mudah diterapkan, sedangkan kriging lebih banyak membutuhkan waktu, namun metode kriging memberikan hasil yang lebih akurat dari struktur spasial data dan 
memberikan informasi berharga dari galat pendugaan (Kravchenko dan Bullock, 1999).

Terdapat beberapa jenis metode kriging, diantaranya (Webster \& Oliver 2007):

\section{Simple Kriging}

Metode kriging yang digunakan jika data memenuhi asumsi stasioner ordo dua atas asumsi stasioner intrinsic dan mean dari populasi diasumsikan konstan dan nilainya diketahui.

\section{Ordinary Kriging}

Metode kriging yang digunakan jika data memenuhi asumsi stasioner ordo dua atau asumsi stasioner intrinsic dan mean dari populasi diasumsikan konstan akan tetapi nilainya tidak diketahui.

\section{Universal Kriging}

Metode kriging yang digunakan jika data tidak memenuhi asumsi stasioner ordo dua atau asumsi stasioner intrinsik. Selain itu, metode ini digunakan jika terdapat trend atau pola pada nilai mean populasi atau ada perubahan pada nilai rata-rata populasi.

\section{Cokriging}

Metode kriging yang digunakan untuk menduga data pada suatu lokasi, akan tetapi metode ini tidak hanya menggunakan peubah utama (primary variables), tapi juga satu atau lebih peubah lain (secondary variables) yang memiliki korelasi spasial dengan peubah.

\section{Block Kriging}

Metode kriging yang digunakan untuk menduga data pada titik-titik di dalam suatu blok area. Nilai dugaan yang dihasilkan merupakan rata-rata nilai dugaan pada titik-titik di blok area tersebut.

\section{Semivariogram}

Ukuran keragaman spasial antar titik contoh dapat ditunjukkan oleh semivarian yang besarnya bergantung pada jarak antar titik. Jarak titik contoh yang kecil akan menghasilkan semivarian yang kecil dan semakin besar jarak antar titik contoh akan menghasilkan semivarian yang semakin besar. Konsep jarak yang digunakan yaitu konsep jarak Euclid.

Plot semivarian sebagai fungsi jarak disebut semivariogram. Semivariogram berfungsi untuk menggambarkan dan memodelkan korelasi spasial antar data. Sebelum menentukan model semivariogram, perlu dilakukan pendugaan terhadap parameter-parameter semivariogram. Parameter tersebut diduga berdasarkan plot semivariogram yang dihasilkan. Menurut Webster \& Oliver parameter yang diperlukan untuk mendiskripsikan model semivariogram yaitu

1. Nugget Effect $\left(\mathrm{C}_{0}\right)$

Pendekatan nilai semivariogram pada jarak disekitar nol.

2. Range (a)

Jarak maksimal dimana masih terdapat korelasi antar data.

3. Siil (C)

Nilai maksimum semivariogram yang diperoleh setelah mencapai range, yaitu jarak maksimal dimana masih terdapat korelasi antar data. Nilai sill umumnya mendekati ragam data dan tidak berubah untuk $\mathrm{h}$ yang tidak terbatas.

Semivariogram teoritis memiliki beberapa model (Cressie 1993, Banerjee et al 2004), yaitu

$$
\begin{aligned}
& \text { 1. Model Nugget Effect } \\
& \qquad \gamma(h)=\left\{\begin{array}{cc}
0, & h=0 \\
C_{0}, & |h|>0
\end{array}\right.
\end{aligned}
$$


Model ini berhubungan dengan data yang tidak berkorelasi satu sama lain meskipun jaraknya sangat dekat.

2. Model Spherical

$$
\gamma(h)=\left\{\begin{array}{lc}
C_{0}+C\left(\frac{3|h|}{2 a}-\frac{3|h|^{3}}{2 a^{3}}\right), & h<a \\
C, & |h| \geq a
\end{array}\right.
$$

3. Model Eksponensial

$\gamma(h) \gamma(h)= \begin{cases}C_{0}+C\left(1-\exp \left(\frac{-|h|}{2 a}\right)\right) & , h<a \\ C, & |h| \geq a\end{cases}$

\section{Model Gaussian}

$$
\gamma(h)=\left\{\begin{array}{lr}
C\left(1-\exp \left(\frac{-h^{2}}{a^{2}}\right)\right), & h<a \\
C, & |h| \geq a
\end{array}\right.
$$

5. Model linear umum

$\gamma(h)=\alpha h, \alpha=$ kemiringan garis

Model linear adalah model semivariogram sederhana yang tidak memiliki sill. Hubungan antara semivariogram dan peragam spasial dinyatakan dalam :

$$
\gamma(h)=C(0)-C(h)
$$

Artinya peragam mempunyai perilaku yang berkebalikan dengan semivariogram. Apabila semivariogram naik untuk suatu jarak pisah tertentu maka peragam akan turun pada jarak pisah tersebut. Apabila pada semivariogram nilai $\mathrm{C}(0)$ adalah sill, maka pada peragam $\mathrm{C}(0)$ meruapakan ragam sampel dari peubah region.
Dari peragam spasial $\mathrm{C}(\mathrm{h})$ dapat dibentuk struktur korelasi spasial $\rho(h)$ dengan perumusan:

$$
\rho(h)=\frac{C(h)}{C(0)}
$$

Plot semivariogram terhadap jarak $\mathrm{h}$ memberikan plot semivariogram eksperimental. Semivariogram eksperimental dari data biasanya bentuknya tidak beraturan sehingga sulit ditafsirkan dan tidak dapat langsung digunakan. Selanjutnya nilai semivariogram eksperimental akan dicocokkan dengan model semivariogram teoritis untuk digunakan dalam penaksiran. Terdapat beberapa perilaku semivariogram eksperimental yang menjadi acuan dalam menentukan model semivariogram teoritis yang sesuai, yaitu :

1. Kelakuan di sekitar origin (titik $(0,0)$ ), yang dibagi menjadi tipe linear dan parabolik.

2. Ada atau tidak adanya sill.

\section{METODE PENELITIAN}

Data

Data yang di gunakan untuk pendugaan menggunakan Ordinary

\begin{tabular}{|c|c|c|c|c|}
\hline \multirow{2}{*}{ KECAMATAN } & \multirow{2}{*}{ DESA } & \multicolumn{2}{|c|}{ LOKASI } & \multirow{2}{*}{ Jumlah Penderita Diare (Des 2009) } \\
\hline & & $\mathbf{X}(\mathbf{E})$ & $\mathbf{Y}(\mathbf{S})$ & \\
\hline \multirow{8}{*}{ 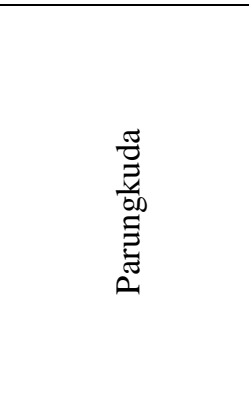 } & Parungkuda & 106.7598 & 6.84528 & 20 \\
\hline & Sundawenang & 106.771 & 6.86994 & 21 \\
\hline & Palasarihilir & 106.7393 & 6.84721 & 14 \\
\hline & Bojongkokosan & 106.7619 & 6.8342 & 14 \\
\hline & Kompa & 106.7621 & 6.82109 & 18 \\
\hline & Pd landeuh & 106.7698 & 6.81578 & 11 \\
\hline & Langensari & 106.7518 & 6.83155 & 23 \\
\hline & Babakanjaya & 106.7604 & 6.80943 & 14 \\
\hline ひ & Cidahu & 106.727 & 6.77286 & 40 \\
\hline
\end{tabular}
Kriging ada pada Tabel dibawah ini.

Tabel 1 Data Jumlah Penderita Diare di Kabupaten Bogor pada Desember 2009 


\begin{tabular}{|c|c|c|c|c|}
\hline \multirow{9}{*}{ KECAMATAN } & \multirow{2}{*}{ DESA } & \multicolumn{2}{|c|}{ LOKASI } & \multirow{2}{*}{ Jumlah Penderita Diare (Des 2009) } \\
\hline & & $\mathbf{X}(\mathbf{E})$ & $\mathbf{Y}(\mathbf{S})$ & \\
\hline & Jayabakti & 106.7396 & 6.79408 & 41 \\
\hline & Pd Tengah & 106.7445 & 6.80054 & 34 \\
\hline & Pd Tonggoh & 106.7525 & 6.79878 & 32 \\
\hline & Pasirdoton & 106.7445 & 6.79112 & 27 \\
\hline & Babakanpari & 106.767 & 6.79473 & 26 \\
\hline & Tangkil & 106.7459 & 6.78046 & 25 \\
\hline & Girijaya & 106.7364 & 6.76586 & 30 \\
\hline \multirow{8}{*}{ 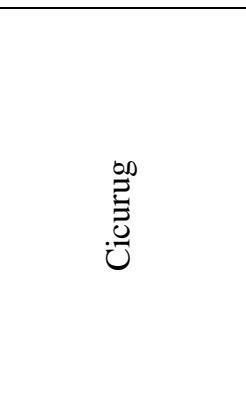 } & \begin{tabular}{|l|} 
Cicurug \\
\end{tabular} & 106.7832 & 6.7835 & 41 \\
\hline & Nyangkowek & 106.7789 & 6.79871 & 38 \\
\hline & Benda & 106.8037 & 6.76486 & 41 \\
\hline & Pasawahan & 106.7782 & 6.67811 & 11 \\
\hline & Purwasari & 106.7842 & 6.7924 & 42 \\
\hline & Tenjoayu & 106.7949 & 6.77253 & 26 \\
\hline & Kutajaya & 106.783 & 6.75518 & 20 \\
\hline & Nanggerang & 106.7946 & 6.78104 & 16 \\
\hline \multirow{6}{*}{ 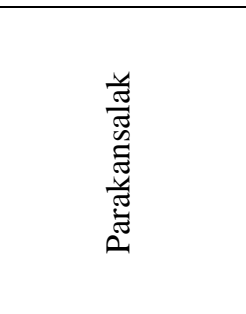 } & Parakansalak & 106.7062 & 6.79897 & 24 \\
\hline & Lebaksari & 106.7199 & 6.79443 & 24 \\
\hline & Sukatani & 106.7026 & 6.82069 & 19 \\
\hline & Sukakersa & 106.708 & 6.80804 & 19 \\
\hline & Bojonglongok & 106.7326 & 6.82214 & 20 \\
\hline & Bojongasih & 106.721 & 6.81545 & 17 \\
\hline \multirow{5}{*}{$\begin{array}{l}\text { D. } \\
\stackrel{0}{0} \\
\stackrel{0}{0} \\
0 \\
00 \\
\tilde{0} \\
\stackrel{0}{0} \\
\infty\end{array}$} & Berekah & 106.709 & 6.84256 & 40 \\
\hline & Bojonggenteng & 106.721 & 6.84325 & 43 \\
\hline & Bojonggaling & 106.7276 & 6.83125 & 15 \\
\hline & Cibodas & 106.7349 & 6.82746 & 23 \\
\hline & Cipanengah & 106.7402 & 6.81309 & 34 \\
\hline
\end{tabular}

\section{Metode}

Secara umum langkah-langkah yang digunakan yaitu:

a. Pemilihan Model Semivariogram

1. Menyiapkan data yang akan kita analisis, kemudian memasukannya ke dalam software analisis yaitu GS plus for trial.

2. Membangun grafik Semivariogram dari data

3. Mendapatkan empat Model Semivariogram yaitu : Model Linear, Spherical, Eksponensial dan Gaussian
4. Memperhatikan nilai R-square dan Jumlah Kuadrat Galat dari masingmasing model

5. Memilih Model Gaussian sebagai model terbaik karena memiliki nilai $\mathrm{R}$-square terbesar dan dan Jumlah Kuadrat Galat terkecil.

b. Membuat model pendugaan dengan menggunakan Kriging

1. Dengan menggunakan Model Semivariogram Gaussian, maka kami membuat model pendugaan Interpolasi dengan menggunakan Interval pada sumbu $X$ sebesar 0.001445 dan sumbu $\mathrm{Y}$ sebesar 0.00274 . Nilai tersebut berasal dari 
hasil bagi Jangkauan masing-maisng nilai minimum dan maksimum koordinatnya.

2. Mendapatkan nilai-nilai dugaan hasil Kriging

3. Memperoleh Grafik 3-dimensi dan 2dimensi hasil Kriging

4. Menginterpretasikan hasil dugaan Kriging berdasarkan kontur yang di hasilkan pada Grafik. Memperhatikan nilai-nilai tertinggi dan terendah dari Kontur.

\section{HASIL DAN PEMBAHASAN}

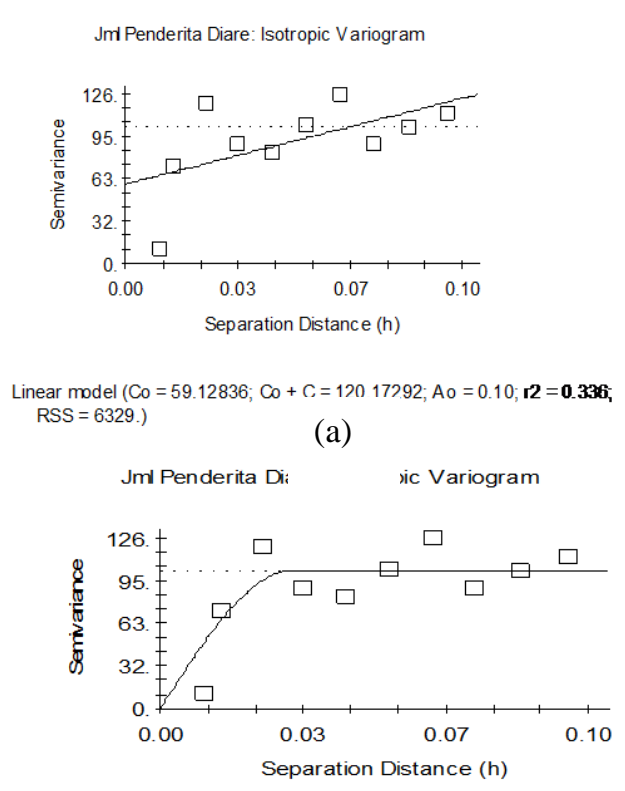

Spherical model $(C O=0.10000 ; C O+C=102.10000 ; A o=0.03 ; \mathbf{r} 2=\mathbf{0 . 7 1 5} ;$ RSS $=2743$. $)$
$\quad$ RSS $=3357$.

Gambar 1. Semivariogram isotropic untuk model (a) linear, (b) spherical, (c) eksponensial, dan (d) Gaussian

Tabel 2. Nilai $\mathrm{R}^{2}$ dan Jumlah Kuadrat Galat (JKG) h (b) iterpolasi jumlah penderitá uıaı

\begin{tabular}{ccc}
\hline Model & $\mathrm{R}^{2}$ & $\mathrm{JKG}$ \\
\hline Linear & 0.336 & 6329 \\
Eksponensial & 0,602 & 3958 \\
Sphirakel & 0.715 & 3357 \\
Gaussian & 0.736 & 2743 \\
\hline
\end{tabular}

Dari Tabel 2, dapat dilihat bahwa model Gaussian merupakan model yang
Dalam penelitian ini, variogram yang digunakan adalah model Linear, Eksponensial, Spherikal dan Gaussian. Model variogram yang terpilih merupakan model dengan jumlah kuadrat sisaan (RMSE) terkecil dan koefisien determinasi $\left(\mathrm{R}^{2}\right)$ yang relatif besar. Variogram data jumlah penderita diare pada bulan Juni tahun 2009 disesuaikan dengan modelmodel variogram Linear, Eksponensial, Sphirakel dan Gaussian menghasilkan nilai ragam dan nilai RMSE seperti yang dapat dilihat dalam gambar di bawah ini.

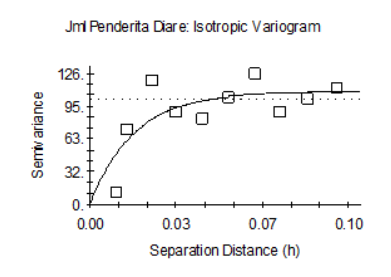

Exponential model $(C 0=0.10000 ; \quad C 0+C=108.30000 ; A 0=0.02, \mathbf{r 2}=\mathbf{0 . 6 0 2}$,
RSS $=3958$.

(c)

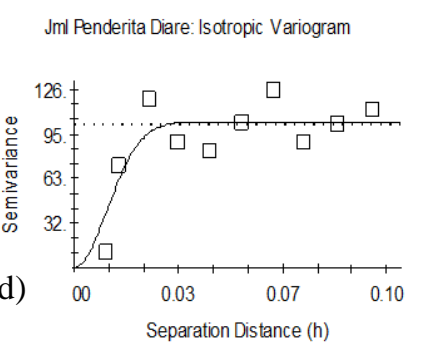

Gaussian model $(C 0=0.10000 ; C 0+C=103.50000 ; A 0=0.02, \mathbf{R}=\mathbf{0 . 7 3 6}$; (a) 1

terbaik. Hal tersebut dikarenakan model Gaussian memiliki nilai $\mathrm{R}^{2}$ yang paling besar dan nilai JKG minimum. Sedangkan untuk ketiga model lainnya, nilai $\mathrm{R}^{2}$ relatif lebih kecil. Dengan demikian dapat disimpulkan bahwa untuk jumlah penderita diare pada bulan Juni tahun 2004 dapat dimodelkan dengan model $s v=103.500(1-$ $\exp \left(\left(\frac{h}{0.026^{2}}\right)\right)$ 
Dari model variogram yang terpilih dapat diperoleh informasi mengenai parameter-parameter geostatistikanya, yaitu nilai Nugget variance $\left(\mathrm{C}_{0}\right)$, Sill $\left(\mathrm{C}_{0}+\mathrm{C}\right)$ dan Range (A). Nilai Nugget variance dan Sill bersifat tetap, sedangkat nilai Range dipengaruhi oleh sudut anisotropik. Model terpilih Gaussian memiliki nilainilai parameter sebagai berikut, disajikan dalam table di bawah ini.

Tabel 3. Nilai parameter-parameter geostatistics

\begin{tabular}{lr}
\hline \multirow{2}{*}{ Model } & \multicolumn{2}{c}{$\begin{array}{c}\text { Jumlah Penderita Diare par } \\
\text { Desember 2009 }\end{array}$} \\
\cline { 2 - 3 } & \multicolumn{2}{c}{ Gaussian } \\
\hline Nugget & 0.100 \\
Sill & 103.500 \\
Range & 0.026 \\
\hline
\end{tabular}

Berdasarkan

Gambar

semivariogram untuk model Gausian (Gambar 1 (d)), data penderita diare pada Desember 2009 mempunyai titik asal yang bukan nol. Hal ini mengindikasikan bahwa data mengandung Nugget effect. Nugget effect merupakan nilai yang timbul karena adanya galat ragam atau galat mikro, misalnya galat kesalahan yang terjadi karena kesalahan peniliti atau dalam pencatatan. Dalam model ini, nilai Nugget effect sebesar 0.100 . Variogram model Gaussian mencapai jarak Sill pada 0.026 dengan Sill sebesar 103.500. Setelah variogram mencapai nilai tersebut, grafik menuju suatu nilai semivariance yang konstan. Hal tersebut mengindikasikan bahwa tidak ada korelasi lagi antar jumlah penderita diare dengan lokasi.
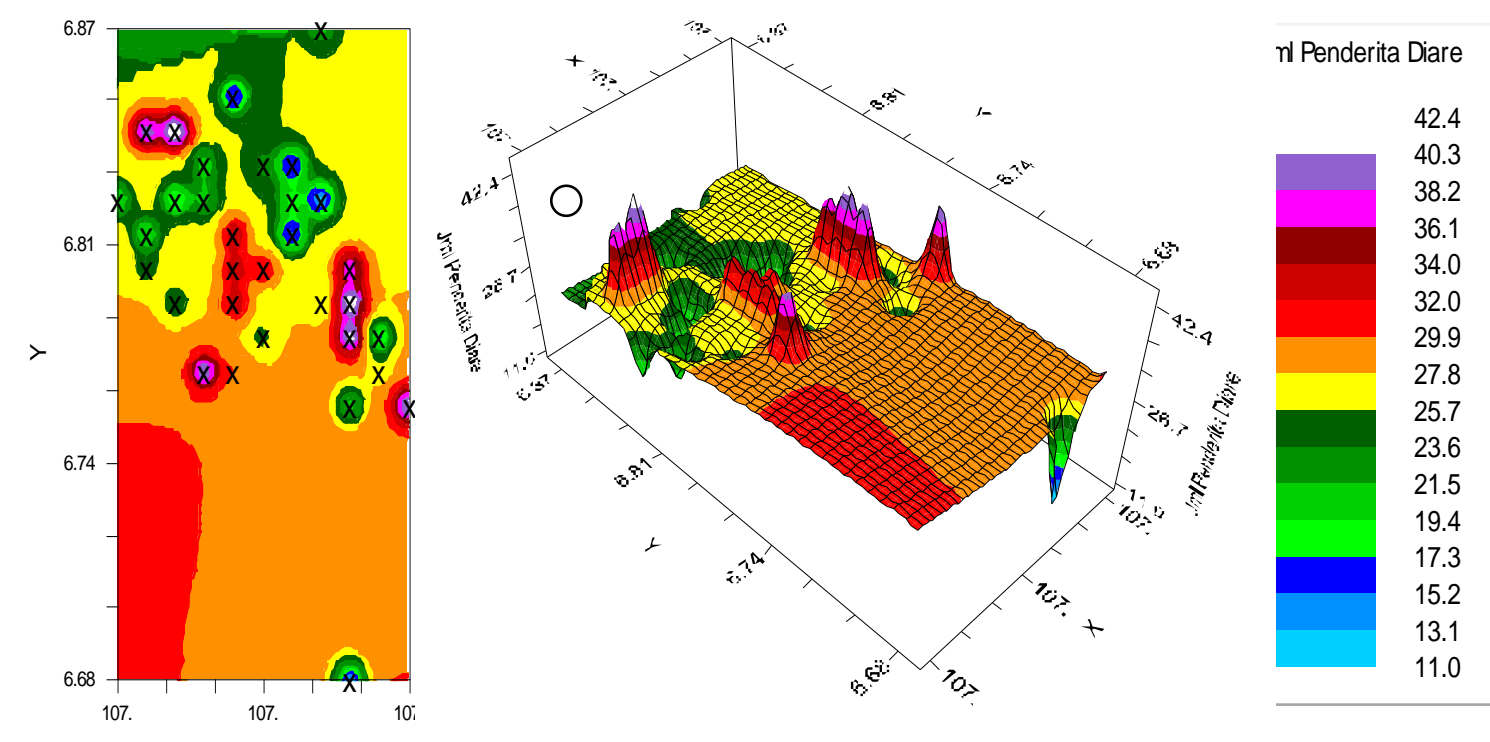

Gambar 2. Peta Kontur Interpolasi Jumlah Penderita Diare dengan Ordinary Krigin 
Berdasarkan Gambar di atas, dapat dilihat bahwa daerah yang memiliki jumlah penderita diare paling banyak terdapat di sekitar Desa Barekah dan Bojonggenteng ditandai dengan warna kontur Putih dengan kisaran jumlah penderita diare yaitu $40-42$ orang. Penurunan jumlah penderita diare ditunjukkan dengan perubahan warna seperti pada Gambar 3.

\section{SIMPULAN}

Penelitian ini bertujuan untuk mengetahui pola penyebaran penyakit diare di Kabupaten Bogor. Metode yang sesuai dengan tujuan penelitian ini adalah Ordinary Kriging. Langkah pertama yaitu menentukan model variogram terpilih berdasarkan jumlah kuadrat galat (JKG) terkecil dan koefisien determinasi $\left(\mathrm{R}^{2}\right)$ terbesar. Model yang terpilih adalah model Gaussian karena memiliki JKG dan $\mathrm{R}^{2}$ berturut-turut adalah 2743 dan 0.736 lebih baik dibandingkan dengan model yang lain. Selanjutnya untuk mengetahui sebaran penyakit diare di Kabupaten Bogor dengan melihat hasil countour plot. Berdasarkan countour plot, daerah yang memiliki jumlah penderita diare paling banyak terdapat di sekitar Desa Barekah dan Bojonggenteng ditandai dengan warna kontur Putih dengan kisaran jumlah penderita diare yaitu 40 42 orang.

Daerah yang memiliki jumlah penyakit diare terbanyak mengindikasikan bahwa daerah tersebut memiliki hubungan dengan jumlah penyakit diare di daerah sekitarnya. Oleh karena itu, daerah tersebut perlu mendapatkan prioritas dalam hal perbaikan sanitasi air, penyuluhan ke masyarakat dan peningkatan layanan kesehatan.

\section{DAFTAR PUSTAKA}

Banerjee, S., B. P. Carlin, and A. E. Gelfand. 2004. Hierarchical Modeling and Analysis for Spatial Data. Chapman and Hall/CRC, Florida, U.S.A.

Cressie, N. A. C. 1993. Statistics for Spatial Data. John Willey \& Sons, Inc. New York

Kravchenko, A. and D. G. Bullock. 1999. A Comparative Study of Interpolation Methods for Mapping Soil Properties. Agron. J. 91: 393:400

Sunoto. (1987). Social Behavioral Aspek of Diarrheal disease in the Community.

Webster, R. and Oliver M.A. : Geostatistics for Environmental Scientists. Second Edition. Wiley, Chichester (2007)

Wolinsky, Frederic D. (1988). The Sociology of Health Principles, Practitioners and Issues. New Jersey: Prentice Hall. 